\title{
PRODUTIVIDADE, QUALIDADE DOS FRUTOS E DISTRIBUIÇÃO DO SISTEMA RADICULAR DA MELANCIA EM DIFERENTES SISTEMAS DE CULTIVO(1)
}

\author{
Marta Rodrigues da Rocha ${ }^{(2)}$, Flávio Luiz Foletto Eltz ${ }^{(3)}$, \\ Michele Silva dos Santos ${ }^{(4)}$, Pedro Vanti da Rocha ${ }^{(5)}$ \& Rafael \\ Ziani Goulart ${ }^{(6)}$
}

\begin{abstract}
RESUMO
A melancia é cultivada principalmente por pequenos produtores, em solos arenosos sob preparo convencional, com ocorrência de altas taxas de erosão, já que a cultura não forma dossel vegetativo capaz de cobrir inteiramente o solo. Com o objetivo de avaliar a cultura da melancia (Citrullus lanatus $\mathrm{L}$.) em diferentes sistemas de cultivo, sobre um Argissolo Vermelho distrófico arênico na Depressão Central do RS, foi desenvolvido um experimento durante o ano agrícola 2008/2009 com a cultivar Crimson Sweet. Em parcelas de $48 \mathrm{~m}^{2}$ e delineamento em blocos ao acaso com quatro repetições, foram testados os seguintes sistemas de cultivo: preparo convencional (PC), plantio direto (PD), PD escarificado com uma haste de escarificador (PD1H), PD escarificado com duas hastes de escarificador (PD2H), PD escarificado com três hastes de escarificador (PD3H), PD escarificado com quatro hastes de escarificador (PD4H) e PD escarificado com cinco hastes de escarificador (PD5H), com espaçamento entre hastes de $0,35 \mathrm{~m}$. Os dados foram comparados pelo teste de Duncan $(p<5 \%)$. A melancia foi semeada em novembro de 2008 , com espaçamento de 2,20 x $0,75 \mathrm{~m}$, sobre palhada de aveia-preta (Avena strigosa). Além da produtividade de melancia, considerando os frutos comercializáveis (> $6 \mathrm{~kg}$ ), foram determinadas a área superficial e a distribuição do sistema radicular no perfil do solo perpendicular à linha de semeadura (30 e $60 \mathrm{~d}$ após a semeadura). Também foram determinadas a densidade do solo e a resistência à penetração após o ciclo. No tratamento $\mathrm{PC}$ obteve-se a maior produtividade (126 t ha-1), diferenciando-se estatisticamente dos demais. A área total de raízes aumentou com a intensidade de mobilização e área mobilizada de solo, exceto para o tratamento PD4H. No tratamento PC, a densidade do solo não
\end{abstract}

\footnotetext{
(1) Parte da Dissertação de Mestrado da primeira autora vinculada ao programa de Pós-Graduação, com apoio financeiro do CNPQ. Recebido para publicação em 10 de dezembro de 2010 e aprovado em 3 de maio de 2011.

(2) Eng. Agr., MSc em Ciência do Solo, PPG em Ciência do Solo, Universidade Federal de Santa Maria - UFSM. Campus Universitário, CEP 97105-900 Santa Maria (RS). E-mail: marta.da.rocha@gmail.com

(3) Eng.-Agr., PhD., Professor Titular do Departamento de Solos, UFSM. E-mail: flavioeltz@gmail.com

(4) Eng. Agr., MSc em Engenharia Agrícola, PPG em Engenharia Agrícola, UFSM. E-mail: micheleagrícola@yahoo.com.br

(5) Aluno de graduação em Agronomia, UFSM. Bolsista FAPERGS. E-mail: pedrovanti@bol.com.br

${ }^{(6)}$ Aluno de graduação em Agronomia, UFSM. Bolsista voluntário. E-mail: rafaelzgoulart@hotmail.com
} 
mostrou diferença em profundidade, porém nos demais tratamentos houve diferença entre a camada de 0-5 $\mathrm{cm}$ e as mais profundas. A resistência à penetração na camada de $0-10 \mathrm{~cm}$ foi menor, o que pode ter favorecido a maior concentração de raízes nessa camada.

Termos de indexação: propriedades físicas, escarificação, plantio direto.

\title{
SUMMARY: FRUIT YIELD AND QUALITY AND ROOT SYSTEM DISTRIBUTION OF WATERMELON UNDER DIFFERENT CULTIVATION SYSTEMS
}

\begin{abstract}
The watermelon is cultivated mainly by small producers, in sandy soils under conventional tillage, with occurrence of high erosion taxes, since the crop doesn't form canopy capable to cover the soil entirely. Watermelon (Citrullus lanatus L.) was evaluated under different cultivation systems on an Ultisol in the Central Depression of RS, Brazil, in an experiment in the 2008/2009 growing season. On $48 \mathrm{~m}^{2}$ plots in a randomized block design with four repetitions, the following cultivation systems were tested: conventional tillage (CT), no-tillage (NT), NT chiseled with one chisel shank (NT1S), NT chiseled with two shanks (NT2S), NT chiseled with three shanks (NT3S), NT chiseled with four shanks (NT4S), NT chiseled with five shanks (NT5S); the distance between chisel shanks was $0.35 \mathrm{~m}$. Data were analyzed by the Duncan test $(p<5 \%)$. Watermelon was sown in November 2008, in a spacing of $2.20 \times 0.75 \mathrm{~m}$, on black oat straw (Avena strigosa). Apart from the watermelon yield of marketable fruits (> $6 \mathrm{~kg})$, the root surface area and root system distribution in the soil profile perpendicular to the sowing line were determined 30 and 60 d after sowing. Besides, some soil physical properties (soil density and resistance to penetration) were determined after the

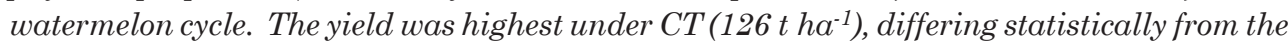
other treatments. The total root area increased with intensity and area of soil mobilization, except in the NT4S treatment. In the CT treatment, no difference in depth was observed, but in the other treatments the 0-5 cm layer differed from the deeper layers. Resistance to penetration in the 0-10 cm layer was lower, which may be related to the higher root concentration in that layer.
\end{abstract}

Index terms: physical properties; chiseling, no-tillage.

\section{INTRODUÇÃO}

No Rio Grande do Sul, a melancia (Citrullus lanatus) é cultivada em solos arenosos, onde o sistema de preparo convencional com aração e gradagens é o mais usado. O preparo convencional do solo favorece a erosão hídrica, já que deixa o solo exposto à ação dos agentes erosivos, tendo em vista que a cultura da melancia não forma um dossel vegetativo capaz de cobrir inteiramente o solo, o que leva as áreas com cultivo dessa hortaliça a processos erosivos intensos (Eltz et al., 2005).

Alvarenga \& Resende (2002) classificam os frutos de melancia, conforme o peso, em grandes $(>9 \mathrm{~kg})$, médios $(6-9 \mathrm{~kg})$ e pequenos (<6 kg); frutos com mais de $7 \mathrm{~kg}$ obtêm os melhores preços. O principal açúcar encontrado nos frutos de melancia é a frutose. O acúmulo de açúcar ocorre de 20 a 36 d após a abertura das flores (antese). O conteúdo de frutose e glicose tende a reduzir após $28 \mathrm{~d}$ a partir da antese, enquanto o conteúdo de sacarose e açúcares totais pode aumentar no período de 20 a $60 \mathrm{~d}$ após a antese, dependendo da cultivar (Elmostrom \& Davis, 1981; Brown Jr. \&
Summers,1985; Araújo Neto et al., 2000). Os sólidos solúveis totais variam entre as diferentes cultivares de melancia. As mais antigas situam-se abaixo de $9^{\circ} \mathrm{Brix}$, e as variedades mais recentes podem apresentar valores acima de $12^{\circ}$ Brix (Mohr, 1986). Esses valores dependem das condições ambientais, pois o excesso de água no estádio final do ciclo pode resultar em frutos pouco doces, resultante da maior diluição dos açúcares (Castellane \& Cortez, 1995).

A observação do sistema radicular por meio da abertura de trincheiras é uma maneira simples de se verificar a presença de camadas compactadas no campo, principalmente quando se trata de compactação subsuperficial ou "pé-de-arado". Quando a compactação limita o crescimento radicular, é possível observar grande concentração de raízes na camada superficial, pois elas não conseguem ultrapassar a camada compactada, o que deixa a cultura suscetível a períodos de estiagem (Sá \& Santos Júnior, 2005).

A qualidade física do solo corresponde à capacidade de o mesmo em promover condições favoráveis ao crescimento e desenvolvimento ao sistema radicular 
das plantas (Choudhury \& Oliveira, 1982; Neves Júnior, 2005; Prevedello, 2008), observando a influência do preparo do solo na produção de melancia e na compactação em um Latossolo VermelhoAmarelo, constataram que a densidade do solo de $1,68 \mathrm{~kg} \mathrm{dm}^{-3}$ restringiu a penetração e o crescimento radicular da cultura da melancia.

A densidade do solo é uma propriedade que pode ser utilizada como índice de compactação do solo, sendo muito usada nas avaliações da estrutura dos solos (Scapini et al., 1998). Limites críticos de densidade do solo ao crescimento radicular são variáveis para diferentes tipos de solos e plantas (Rubin et al., 1998). Reinert et al. (2001) sugerem como limites críticos de densidade do solo $1,45 \mathrm{~kg} \mathrm{dm}^{-3}$ para solos com horizonte de textura argilosa (mais de $55 \%$ de argila), $1,55 \mathrm{~kg} \mathrm{dm}^{-3}$ para solos com horizonte de textura média (argila entre 20 e $55 \%$ ) e $1,65 \mathrm{~kg} \mathrm{dm}^{-3}$ para solos com textura arenosa (menos de $20 \%$ de argila).

O objetivo deste trabalho foi avaliar a produtividade, a qualidade dos frutos e a distribuição do sistema radicular da melancia em diferentes sistemas de cultivo do solo em dois estádios do ciclo vegetativo, bem como a resistência à penetração e a densidade do solo nos diferentes sistemas de cultivo e em profundidade sobre a linha de semeadura após o ciclo da melancia.

\section{MATERIAL E MÉTODOS}

O experimento foi desenvolvido em Argissolo Vermelho distrófico arênico na região central do Rio Grande do Sul, no município de Dilermando de Aguiar; o clima da região é do tipo "Cfa" subtropical úmido sem estiagem, segundo classificação de Köppen (Moreno, 1961), com precipitações pluviais médias anuais de $1.382 \mathrm{~mm}$, temperaturas médias anuais entre 17,9 e $19,2^{\circ} \mathrm{C}$ e umidade relativa do ar média anual de 71 a $82 \%$ (Cogo et al., 2006). As parcelas de $6 \times 8 \mathrm{~m}$ foram distribuídas em delineamento de blocos ao acaso com quatro repetições, e os dados, submetidos ao teste de Duncan a $5 \%$.

Os tratamentos consistiram em diferentes intensidades de mobilização do solo, sendo eles: preparo convencional (PC); plantio direto (PD); plantio direto escarificado com uma haste de escarificador (PD1H); plantio direto escarificado com duas hastes de escarificador (PD2H); plantio direto escarificado com três hastes de escarificador (PD3H); plantio direto escarificado com quatro hastes de escarificador (PD4H) e plantio direto escarificado com cinco hastes de escarificador (PD5H). O espaçamento entre hastes do escarificador era de $0,35 \mathrm{~m}$.

A semeadura da melancia foi realizada com um conjunto mecanizado de trator e semeadora de plantio direto, com espaçamento entre linhas de $2,20 \mathrm{~m}$ e $0,75 \mathrm{~m}$ entre plantas na linha. A variedade cultivada foi a Crimson Sweet, e a adubação foi de $500 \mathrm{~kg} \mathrm{ha}^{-1}$ da formulação NPK 5-20-30, seguindo recomendação da SBCS.CQFS (2004). Nos tratamentos de escarificação com número ímpar de hastes, a linha de semeadura da melancia coincidiu com o sulco de escarificação central. Quando o número de hastes era par, a linha de semeadura ficou entre os sulcos centrais.

O ponto de colheita dos frutos foi determinado pelo amadurecimento, tendo sido usado como referência o ressecamento da gavinha inserida na axila da folha com o pedúnculo do fruto (Carvalho, 2005); posteriormente, eles foram pesados em campo em balança de precisão, sendo então determinados: produção de frutos e peso médio dos frutos comercializáveis (> $6 \mathrm{~kg}$ ), sólidos solúveis totais, $\mathrm{pH}$ e acidez total titulável. As determinações de sólidos solúveis, $\mathrm{pH}$ e acidez titulável foram realizadas em laboratórios do Departamento de Ciência e Tecnologia dos Alimentos da UFSM. Para isso, três frutos por parcela tiveram retiradas partes do "coração" dos frutos, as quais foram maceradas, e o suco, separado do tecido fibroso. Os sólidos solúveis totais foram determinados por refratometria, com refratômetro de Atago com escala graduada de $0-30^{\circ}$ Brix. A acidez potenciométrica $(\mathrm{pH})$ foi determinada em potenciômetro digital em temperatura de $25^{\circ} \mathrm{C}$, e a acidez total titulável, por titulação (Instituto Adolfo Lutz, 2005).

Para determinação da distribuição do sistema radicular da melancia a partir de imagens digitais, foram abertas trincheiras de $1,20 \times 0,50 \mathrm{~m}$, paralelas à linha da cultura e distantes aproximadamente $3 \mathrm{~cm}$ do colo da planta, expondo-se o sistema radicular. A coleta de imagens foi realizada em dois momentos do ciclo da melancia: a primeira, $30 \mathrm{~d}$ após a semeadura, e a segunda, $60 \mathrm{~d}$ após a semeadura, com uma repetição por parcela, ou seja, quatro repetições por tratamento. O método de coleta das amostras é descrito por Jorge \& Crestana (2006) e adaptado às necessidades do trabalho. Para cada perfil, foram coletadas aproximadamente 20 imagens em câmera digital comum, trabalhadas na ferramenta Paint (Microsoft) e processadas no software SIARCS 3.0® (Crestana et al., 1994; Jorge \& Crestana, 1996). As raízes foram quantificadas em área superficial, distribuídas em área perpendicular à linha de semeadura e separadas em classes longitudinais (20 em $20 \mathrm{~cm}$ à esquerda (E) e à direita (D) do colo da planta) e em profundidade $(10 \mathrm{em} 10 \mathrm{~cm})$.

Amostras de solos indeformadas, com a estrutura preservada, foram coletadas com cilindros volumétricos em aço, conhecido como "anel de Kopeck", para determinação da densidade do solo, seguindo método descrito em Embrapa (1997), nas profundidades de $0-5,5-10,10-15,15-20$ e 20 $25 \mathrm{~m}$ de profundidade, com quatro repetições por tratamento. A amostragem foi realizada sobre a linha de semeadura da melancia, após o ciclo da cultura. 
A resistência à penetração foi determinada com Penetrômetro Georreferenciado PNT-2000, com ponta cônica de $30^{\circ}$ e com área do cone de $129 \mathrm{~mm}^{2}$, segundo normas ASAE S313.3. As observações foram realizadas a cada $10 \mathrm{~cm}$ de profundidade (utilizandose média de $5 \mathrm{~cm}$ ), até uma profundidade máxima de $40 \mathrm{~cm}$. Perpendiculares à linha de semeadura e distantes entre si $20 \mathrm{~cm}$, foram amostrados sete pontos, sendo um sobre a linha de semeadura, à direita 20,40 e $60 \mathrm{~cm}$ e à esquerda 20,40 e $60 \mathrm{~cm}$, tendo como referência a linha de semeadura, com três repetições por parcela. A umidade gravimétrica foi determinada a partir de coleta de amostras de solo, com o auxílio de um trado calador, as quais foram armazenadas em embalagens hermeticamente fechadas, na profundidade de $0-20 \mathrm{~cm}$, segundo método descrita em Embrapa (1997).

\section{RESULTADOS E DISCUSSÃO}

Com o tratamento PC obteve-se a maior produtividade de frutos de melancia (Figura 1) entre os sistemas de manejo avaliados (126,5 $\left.\mathrm{t} \mathrm{ha}^{-1}\right)$, diferindo estatisticamente dos demais tratamentos. Houve tendência de aumento de produtividade com o aumento de área mobilizada pelo número de hastes do escarificador usadas em cada tratamento, porém não houve diferença estatística significativa; PD1H, PD2H, PD3H, PD4H e PD5H produziram 83,4; 84,9; 85,$8 ; 91,5$; e $99,7 \mathrm{t} \mathrm{ha}^{-1}$, respectivamente.

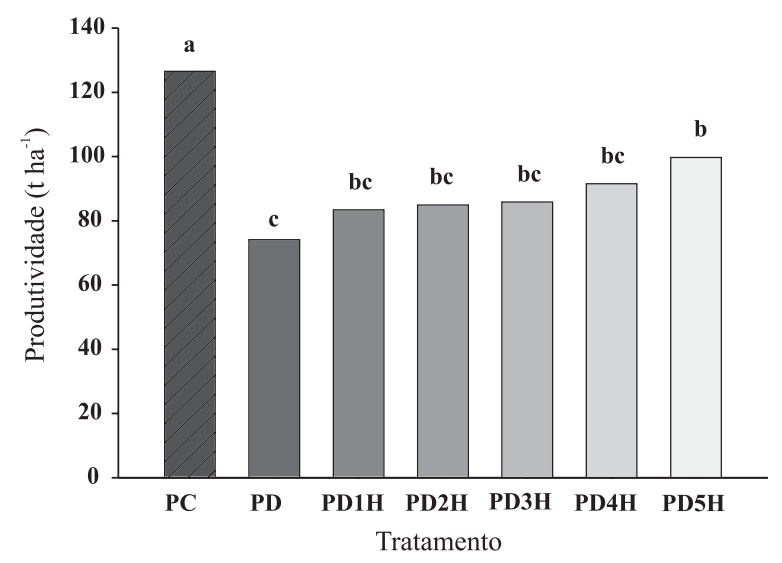

Figura 1. Produtividade de melancia em diferentes sistemas de cultivo (PC: preparo convencional; PD: plantio direto; PD1H: PD escarificado com uma haste de escarificador; PD2H: PD escarificado com duas hastes; PD3H: PD escarificado com três hastes; PD4H: PD escarificado com quatro hastes; PD5H: PD escarificado com cinco hastes). Colunas com a mesma letra não diferem entre si pelo teste de Duncan a 5 \%.
O tratamento PD causou a menor produtividade (74,1 t ha $\left.{ }^{-1}\right)$, diferindo de PC e PD5H, porém não se diferenciando dos demais. Segundo dados do IBGE (2010), a produtividade média de melancia do Rio Grande do Sul no mesmo ano agrícola (2008/2009) foi de $25 \mathrm{t} \mathrm{ha}^{-1}$, o que corresponde aproximadamente a um terço da produtividade obtida no tratamento PD.

Quanto ao peso médio dos frutos (PMF) comercializáveis (Figura 2), não houve diferença significativa entre os tratamentos, sendo encontrados valores na faixa de 10 a $11 \mathrm{~kg}$, que são classificados como "extras" ou "especiais" (Carvalho, 2005) e têm maior valor comercial. Não há relação entre PMF e a intensidade de mobilização do solo. Avaliando o efeito do manejo do solo sobre a produção e qualidade da melancia, Eltz et al. (2005) encontraram PMF de $10,08 \mathrm{~kg}$ para os tratamentos com preparo convencional e semeadura direta, confirmando que o manejo do solo não tem efeito sobre o PMF.

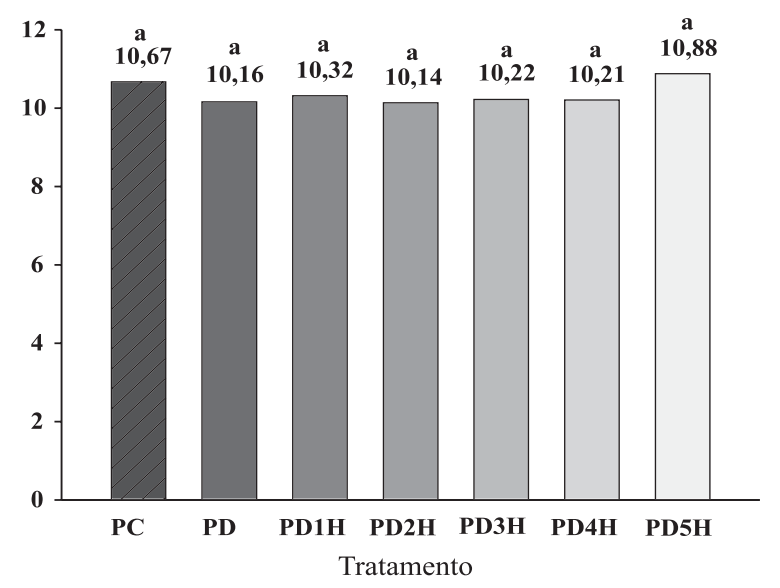

Figura 2. Peso médio dos frutos comercializáveis $(>6 \mathrm{~kg})$ de melancia em diferentes sistemas de cultivo (PC: preparo convencional; PD: plantio direto; PD1H: PD escarificado com uma haste de escarificador; PD2H: PD escarificado com duas hastes; PD3H: PD escarificado com três hastes; PD4H: PD escarificado com quatro hastes; PD5H: PD escarificado com cinco hastes). Colunas com a mesma letra não diferem entre si pelo teste de Duncan a $5 \%$.

A acidez total titulável tende a aumentar com o crescimento do fruto até seu completo desenvolvimento fisiológico, quando então começa a decrescer com o amadurecimento (Sass, 1993). As diferentes intensidades de mobilização do solo promovidas pelos tratamentos avaliados neste trabalho não alteraram a qualidade do fruto, determinada pela análise dos sólidos solúveis totais, acidez total titulável e $\mathrm{pH}$, não diferindo significativamente entre si (Quadro 1). 
Quadro 1. Sólidos solúveis totais ( $\left.{ }^{\circ} \mathrm{Brix}\right)$, acidez total titulável e pH a $25^{\circ} \mathrm{C}$ dos frutos de melancia em diferentes sistemas de cultivo do solo

\begin{tabular}{lrrr} 
Tratamento & $\begin{array}{c}\text { Sólidos solúveis } \\
\text { totais }{ }^{\circ} \text { Brix }\end{array}$ & $\begin{array}{c}\text { Acidez total } \\
\text { titulável }\end{array}$ & pH a $25{ }^{\circ} \mathbf{C}$ \\
\hline PC & $10,2 \mathrm{a}$ & $9,1 \mathrm{a}$ & $5,48 \mathrm{a}$ \\
PD & $10,0 \mathrm{a}$ & $9,4 \mathrm{a}$ & $5,41 \mathrm{a}$ \\
PD 1H & $10,3 \mathrm{a}$ & $10,2 \mathrm{a}$ & $5,46 \mathrm{a}$ \\
PD 2H & $9,8 \mathrm{a}$ & $8,3 \mathrm{a}$ & $5,53 \mathrm{a}$ \\
PD 3H & $10,2 \mathrm{a}$ & $9,9 \mathrm{a}$ & $5,46 \mathrm{a}$ \\
PD 4H & $10,5 \mathrm{a}$ & $11,1 \mathrm{a}$ & $5,47 \mathrm{a}$ \\
PD 5H & $10,3 \mathrm{a}$ & $9,6 \mathrm{a}$ & $5,45 \mathrm{a}$ \\
\hline
\end{tabular}

PC: preparo convencional; PD: plantio direto; PD1H: PD escarificado com uma haste de escarificador; PD2H: PD escarificado com duas hastes; PD3H: PD escarificado com três hastes; PD4H: PD escarificado com quatro hastes; PD5H: escarificado com cinco hastes. Médias seguidas pela mesma letra na coluna não diferem pelo teste de Duncan a $5 \%$.

O teor de sólidos solúveis totais para a cultivar Crimson Sweet relatado por Villa (2001) é de $10^{\circ}$ Brix, como verificado no tratamento PD. Norton et al. (1995), em trabalho realizado no Alabama, Estados Unidos, observaram $10,4^{\circ}$ Brix para a mesma cultivar, ao passo que Fernandez \& Capato (2000) encontraram 9,6 a $10,4^{\circ}$ Brix no Estado do Mato Grosso. Lopes (2002), em experimento desenvolvido na Depressão Central do RS, encontrou $4,8^{\circ}$ Brix para essa cultivar, relatando altas precipitações pluviais na fase final do ciclo, o que indica influência das condições climáticas sobre a qualidade dos frutos, devido a uma maior diluição dos açúcares.

Com base na classificação dos frutos descrita por Carvalho (2005), em que são comercializáveis apenas os frutos maiores de $6 \mathrm{~kg}$, classificados como "médios" os frutos com peso na faixa de 6 a $9 \mathrm{~kg}$ e "grandes" aqueles com mais de $9 \mathrm{~kg}$, observou-se diferença significativa nas avaliações tomadas como padrão de qualidade dos frutos, em que os frutos classificados como grandes são de melhor qualidade (Quadro 2), confirmando resultados obtidos por Araújo Neto et al. (2000), os quais afirmam que a qualidade de frutos de melancia da variedade Crimson Sweet é influenciada pelo tamanho do fruto; a melhor qualidade foi encontrada em frutos médios $(6,94 \pm 0,77 \mathrm{~kg})$ e grandes $(9,78 \pm 1,02 \mathrm{~kg})$.

A distribuição horizontal do sistema radicular da melancieira em área superficial de raiz $\left(\mathrm{m}^{2}\right) 30 \mathrm{~d}$ após a semeadura (Figura 3a) apresentou diferença estatística nas faixas $0,5-0,3 \mathrm{E}$ e $0,1-0,3 \mathrm{D}$. Na faixa $0,5-$ $0,3 \mathrm{E}$, o tratamento PC diferenciou-se dos demais tratamentos, que não tiveram raízes nessa faixa. Em 0,1-0,3D os tratamentos PC, PD2H, PD3H e PD5H apresentaram semelhança estatística, porém PC, $\mathrm{PD} 2 \mathrm{H}$ e PD5H não diferiram significativamente de $\mathrm{PD} 1 \mathrm{H}$ e os tratamentos $\mathrm{PC}$ e PD5H não diferiram de $\mathrm{PD}, \mathrm{PD} 1 \mathrm{H}$ e $\mathrm{PD} 4 \mathrm{H}$. As faixas $>0,5 \mathrm{E}$ e $>0,5 \mathrm{D}$ não apresentaram raízes aos $30 \mathrm{~d}$. A melancia tem curva de crescimento sigmoide (Eltz et al., 2005), com crescimento inicial lento e mais rápido após os 40 d, o que é evidenciado pelo baixo crescimento radicular aos $30 \mathrm{~d}$.

Quadro 2. Sólidos solúveis totais ( $\left.{ }^{\circ} \mathrm{Brix}\right)$, acidez total titulável e pH a $25{ }^{\circ} \mathrm{C}$ dos frutos comercializáveis de melancia, segundo a classificação por peso: médio (6-9 kg) e grande (>9 kg)

\begin{tabular}{ccccc}
\hline Classificação & Peso & $\begin{array}{c}\text { Sólidos } \\
\text { solúveis totais } \\
{ }^{\circ} \text { Brix }\end{array}$ & $\begin{array}{c}\text { Acidez } \\
\text { total }\end{array}$ & $\begin{array}{c}\mathbf{p H ~ a} \\
\mathbf{2 5}\end{array}{ }^{\circ} \mathbf{C}$ \\
\hline Médio & $\mathrm{kg}$ & & & \\
Grande & $6-9$ & $9,8 \mathrm{~b}$ & $8,8 \mathrm{~b}$ & $5,39 \mathrm{~b}$ \\
& $>9$ & $10,3 \mathrm{a}$ & $9,8 \mathrm{a}$ & $5,47 \mathrm{a}$
\end{tabular}

Médias seguidas pela mesma letra na coluna não diferem pelo teste de Duncan a $5 \%$.
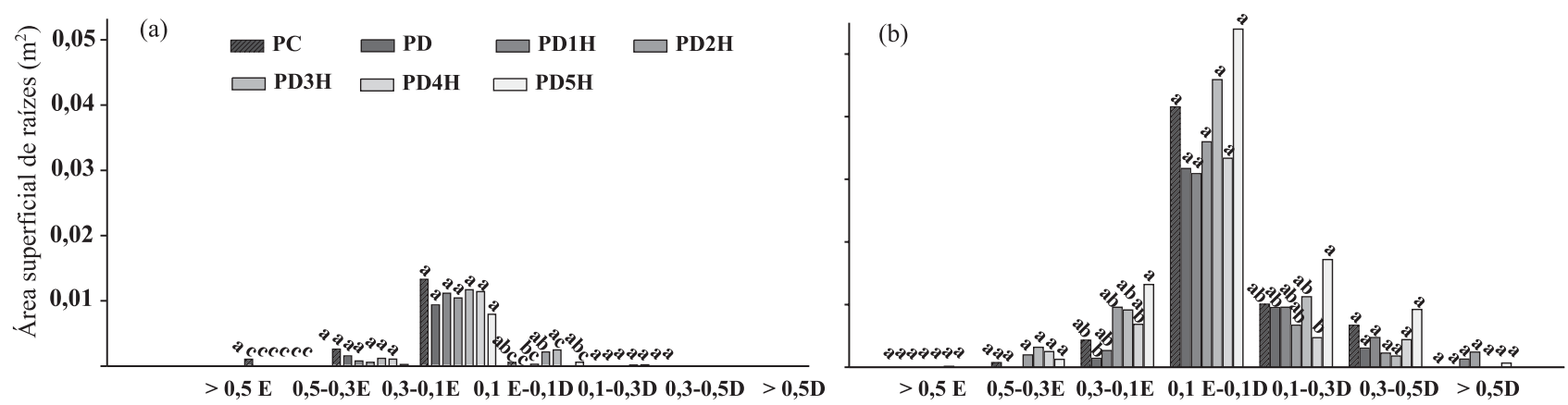

Distância do colo da planta (m)

Figura 3. Distribuição longitudinal do sistema radicular da melancia $30 \mathrm{~d}$ após a semeadura (a) e $60 \mathrm{~d}$ após a semeadura (b). (PC: preparo convencional; PD: plantio direto; PD1H: PD escarificado com uma haste de escarificador; PD2H: PD escarificado com duas hastes; PD3H: PD escarificado com três hastes; PD4H: PD escarificado com quatro hastes; PD5H: PD escarificado com cinco hastes). Barras com a mesma letra na faixa de distância, tendo como referência o colo da planta, não diferem significativamente pelo teste de Duncan a $5 \%$. 
No momento da segunda avaliação, $60 \mathrm{~d}$ após a semeadura, as plantas de melancia estavam em estádio reprodutivo. O sistema radicular seguiu tendência semelhante à encontrada na avaliação feita $30 \mathrm{~d}$ após a semeadura. A maior concentração horizontal de raízes (Figura 3b) ocorreu na faixa $0,1 \mathrm{E}-0,1 \mathrm{D}$, ou seja, $10 \mathrm{~cm}$ à esquerda e à direita ao redor do colo da planta, decrescendo com a distância, não havendo diferença significativa entre os tratamentos. Nas faixas $0,3-$ $0,1 \mathrm{E}$ e $0,1-0,3 \mathrm{D}$ de distribuição horizontal de sistema radicular (Figura 3b), houve diferença significativa entre os tratamentos. Na faixa $0,3-0,1 \mathrm{E}$ o tratamento PD5H diferenciou-se de PD, sendo porém semelhante a PC, PD1H, PD2H, PD3H e PD4H, que por sua vez não se diferenciaram de $\mathrm{PD}$. Na faixa $0,3-0,1 \mathrm{E}$ o tratamento $\mathrm{PD} 5 \mathrm{H}$ apresentou semelhança estatística com PC, PD, PD1H, PD2H e PD3H, e estes, porém,

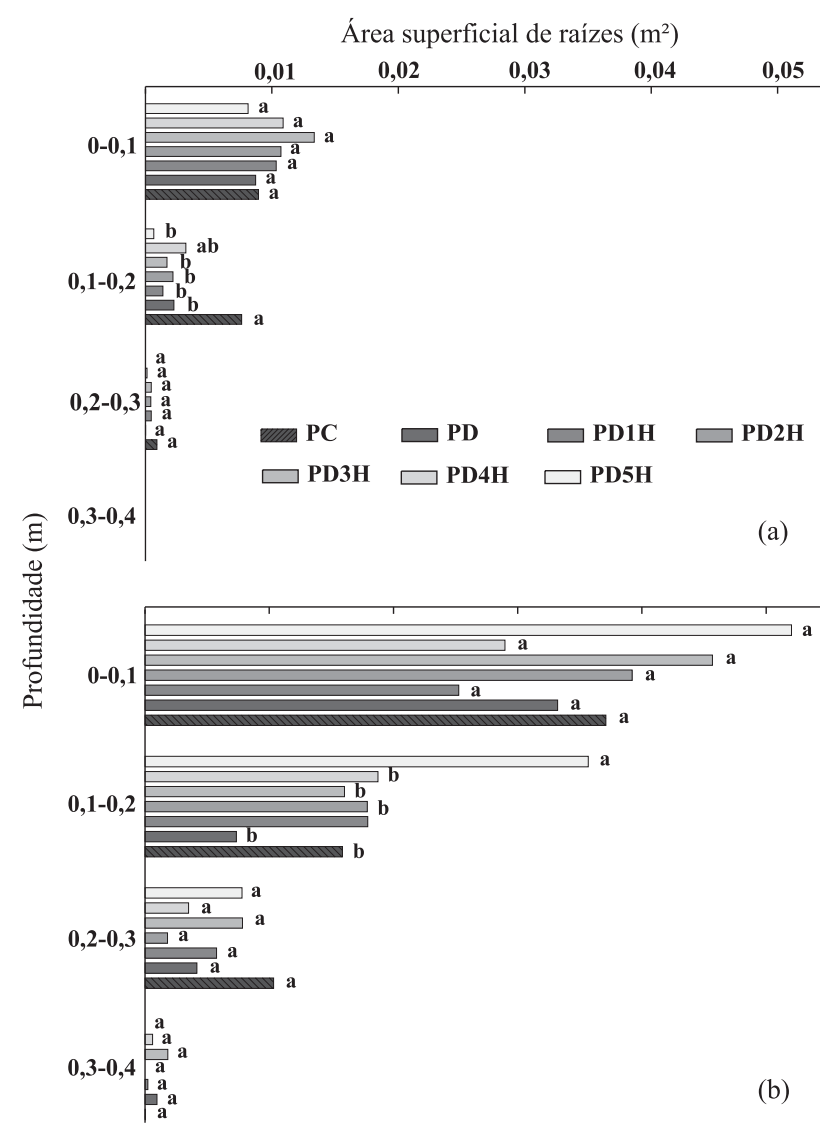

Figura 4. Distribuição do sistema radicular da melancia em profundidade $30 \mathrm{~d}$ após a semeadura (a) e $60 \mathrm{~d}$ após a semeadura (b). (PC: preparo convencional; PD: plantio direto; PD1H: PD escarificado com uma haste de escarificador; PD2H: PD escarificado com duas hastes; PD3H: PD escarificado com três hastes; PD4H: PD escarificado com quatro hastes; PD5H: PD escarificado com cinco hastes). Barras com letras iguais dentro da classe de profundidade entre os tratamentos não diferem significativamente pelo teste de Duncan a $5 \%$. não diferiram de PD4H. Nas demais faixas de distribuição horizontal de sistema radicular de melancieira (> 0,5E; $0,5-0,3 \mathrm{E} ; 0,3-0,5 \mathrm{D}$ e $>0,5 \mathrm{D})$ não houve diferença significativa entre os tratamentos em diferentes sistemas de cultivo. A figura $3 \mathrm{~b}$ mostra grande concentração de raízes próximo ao colo da planta e crescimento radicular mais esparso à medida que se distancia do colo da planta, em todos os sistemas de manejo do solo.

Em profundidade, a distribuição do sistema radicular da melancia atingiu no máximo $30 \mathrm{~cm}$ em 30 d de ciclo (Figura 4a), mostrando o crescimento lento inicial dessa cultura. Foi encontrada diferença estatística entre os tratamentos na faixa de 10-20 cm, onde PC e PD4H apresentaram semelhança entre si, porém $\mathrm{PD} 4 \mathrm{H}$ não diferiu dos demais tratamentos.

A distribuição do sistema radicular da melancieira em profundidade $60 \mathrm{~d}$ após a semeadura (Figura 4b), que coincidiu com o estádio de floração, indicando o máximo desenvolvimento vegetativo, mostrou concentração em torno de $50 \%$ do total de área de raízes na profundidade de $0-10 \mathrm{~cm}$, não sendo significativa a diferença entre os tratamentos. $\mathrm{Na}$ faixa de 10-20 cm, o tratamento PD5H obteve maior área superficial de raiz, diferenciando-se significativamente dos demais. Nas camadas de 20 $30 \mathrm{~cm}$ e $30-40 \mathrm{~cm}$ não houve diferença significativa entre os tratamentos para área superficial de sistema radicular, o que indica que nessa fase do desenvolvimento da cultura as raízes mais próximas do colo são as mais importantes do ponto de vista de absorção de nutrientes para a planta, já que apresentaram área superficial aproximadamente três vezes maior que a das raízes mais distantes do colo. Essa concentração de raízes na camada de $0-10 \mathrm{~cm}$ também pode ser ocasionada pela maior concentração de nutrientes nessa camada, já que a adubação foi colocada na linha de semeadura pela semeadora de plantio direto, além da menor densidade do solo, como pode ser observado no quadro 3.

Observando o tratamento PC, nota-se presença de raiz em torno de $50 \mathrm{~cm}$ para a direita e esquerda em torno do colo da planta (Figura 3a). Em profundidade (Figura 4a), a área superficial de raiz encontrada nas profundidades de 0-10 e 10-20 cm foi similar: 0,0089 e $0,0076 \mathrm{~m}^{2}$, respectivamente; o PC foi o tratamento que teve maior área explorada pelo sistema radicular das plantas de melancia aos $30 \mathrm{~d}$ após a semeadura.

Quanto à distribuição de raízes longitudinalmente (Figura 3a,b), a maior concentração está na faixa $0,1 \mathrm{E}$ 0,1D. Em profundidade (Figura 4), a maior área de raiz foi encontrada até $10 \mathrm{~cm}$, independentemente do manejo do solo, ou seja, aos $30 \mathrm{~d}$, o sistema radicular da cultura da melancia distribui-se em um raio de $10 \mathrm{~cm}$ do colo da planta $(10 \mathrm{~cm}$ à direita, $10 \mathrm{~cm}$ à esquerda e $10 \mathrm{~cm}$ em profundidade). Isto indica a dificuldade das raízes da melancia em se alongar e a necessidade de que o solo esteja sem uma resistência restritiva à penetração, visto o curto ciclo vegetativo da cultura. 
Quadro 3. Densidade do solo em profundidades nos diferentes sistemas de cultivo

\begin{tabular}{|c|c|c|c|c|c|c|c|}
\hline \multirow{2}{*}{ Profundidade } & \multicolumn{7}{|c|}{ Tratamento } \\
\hline & PC & PD & PD 1H & PD 2H & PD $3 \mathrm{H}$ & PD $4 \mathrm{H}$ & PD 5H \\
\hline $\mathrm{cm}$ & & & & $\mathrm{kg} \mathrm{dm}^{-3}$ & & & \\
\hline $0-5$ & $1,26 \mathrm{aA}$ & $1,25 \mathrm{aB}$ & $1,16 \mathrm{aB}$ & $1,24 \mathrm{aB}$ & $1,15 \mathrm{aB}$ & $1,34 \mathrm{aC}$ & $1,10 \mathrm{aB}$ \\
\hline $5-10$ & $1,30 \mathrm{bA}$ & $1,48 \mathrm{abA}$ & $1,43 \mathrm{abA}$ & $1,51 \mathrm{abA}$ & $1,53 \mathrm{aA}$ & $1,61 \mathrm{aA}$ & $1,38 \mathrm{abA}$ \\
\hline $10-15$ & $1,46 \mathrm{abA}$ & $1,60 \mathrm{aA}$ & $1,41 \mathrm{bA}$ & $1,54 \mathrm{abA}$ & $1,48 \mathrm{abA}$ & $1,43 \mathrm{bCB}$ & $1,50 \mathrm{abA}$ \\
\hline $15-20$ & $1,13 \mathrm{aA}$ & $1,59 \mathrm{aA}$ & $1,48 \mathrm{aA}$ & $1,48 \mathrm{aA}$ & $1,44 \mathrm{aA}$ & $1,53 \mathrm{aAB}$ & $1,50 \mathrm{aA}$ \\
\hline $20-25$ & $1,49 \mathrm{aA}$ & $1,54 \mathrm{aA}$ & $1,43 \mathrm{aA}$ & $1,48 \mathrm{aA}$ & $1,47 \mathrm{aA}$ & 1,49 aABC & $1,54 \mathrm{aA}$ \\
\hline
\end{tabular}

PC: preparo convencional; PD: plantio direto; PD1H: PD escarificado com uma haste de escarificador; PD2H: PD escarificado com duas hastes; PD3H: PD escarificado com três hastes; PD4H: PD escarificado com quatro hastes; PD5H: PD escarificado com cinco hastes. Médias seguidas pela mesma letra minúscula na linha e maiúscula na coluna não diferem entre si pelo teste de Duncan a $5 \%$.

A área superficial total do sistema radicular de melancia cultivada em diferentes sistemas de cultivo do solo, aos 30 e $60 \mathrm{~d}$ após a semeadura (Figura 5), apresentou diferença estatística nos dois momentos de avaliação. Aos 30 d o tratamento PC diferenciou-se de PD5H, com 0,017 e 0,008 $\mathrm{m}^{2}$ de raiz, respectivamente, porém ambos não se diferenciaram dos demais tratamentos. Eltz et al. (2005) descreveram o desenvolvimento da melancia pelo comprimento da maior haste, em uma curva sigmoide, sendo lento no primeiro terço do ciclo, o que justifica a pequena área superficial do sistema radicular encontrada aos $30 \mathrm{~d}$ neste trabalho, visto que o crescimento da parte aérea tende a ser proporcional ao crescimento do sistema radicular.

Na avaliação realizada $60 \mathrm{~d}$ após a semeadura, os tratamentos PC, PD1H, PD2H, PD3H e PD5H tive-

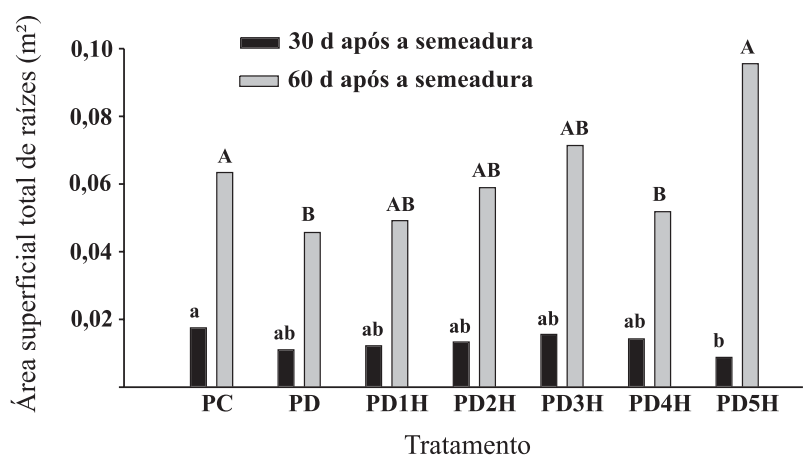

Figura 5. Área superficial total de raiz nos diferentes tratamentos, aos 30 e $60 \mathrm{~d}$ após a semeadura. (PC: preparo convencional; PD: plantio direto; PD1H: PD escarificado com uma haste de escarificador; PD2H: PD escarificado com duas hastes; PD3H: PD escarificado com três hastes; PD4H: PD escarificado com quatro hastes; PD5H: PD escarificado com cinco hastes). Barras com a mesma letra, em minúscula, não diferem significativamente pelo teste de Duncan a $5 \%$ aos $30 \mathrm{~d}$; Barras com a mesma letra, em maiúscula, não diferem significativamente pelo teste de Duncan a $5 \%$ aos $60 \mathrm{~d}$. ram áreas superficiais de raiz semelhantes, porém PC e PD5H tiveram área maior que $\mathrm{PD}$ e $\mathrm{PD} 4 \mathrm{H}$, os quais também não diferiram de PD1H, PD2H e PD3H. Aos $60 \mathrm{~d}$ a planta está em estádio de florescimento, e a maior facilidade de crescimento radicular proporcionado pelo tratamento de maior movimentação do solo mostrou que o PC e o PD5H têm maior área superficial de raízes. Isso também se traduziu em maior produtividade de frutos comercializáveis pelo preparo convencional do solo. Entre os tratamentos de plantio direto escarificado, embora sem diferença estatística, houve tendência de aumento de produtividade com o aumento de movimentação do solo, devido ao aumento do número de hastes e consequente aumento de área superficial de raízes (Figura 5).

A densidade do solo é um atributo frequentemente utilizado para caracterizar a compactação do solo; entretanto, é complicado relacionar a densidade do solo com o crescimento vegetal, uma vez que valores de densidade variam de solo para solo, principalmente em função da sua textura. Solos arenosos apresentam valores de densidade naturalmente mais elevados em relação a solos argilosos (Sá \& Santos Júnior, 2005).

$\mathrm{Na}$ faixa de profundidade de $0-5 \mathrm{~cm}$ não houve diferença estatística significativa na densidade do solo entre os tratamentos (Quadro 3); já na profundidade de 5-10 cm os tratamentos PD3H e PD4H obtiveram os maiores valores de densidade do solo, não se diferenciando de PD, PD1H, PD2H e PD5H, os quais, porém, foram semelhantes ao tratamento PC. Na faixa de 10-15 cm, o tratamento PD não se diferenciou de PC, PD2H, PD3H e PD5H, que por sua vez foram semelhantes a PD1H e PD4H. Nas demais faixas de profundidade não houve diferença estatística entre os tratamentos. Provavelmente, parte da não diferença estatística encontrada deve-se ao longo tempo (sete meses) entre as operações de preparo e a coleta de amostras para determinação desse atributo, devido à estiagem ocorrida após a colheita dos frutos.

Comparando os valores de densidade em profundidade dentro de cada tratamento (Quadro 3), observa-se que a camada de $0-5 \mathrm{~cm}$ diferiu 
significativamente das demais profundidades nos tratamentos PD, PD1H, PD2H, PD3H e PD5H. No tratamento $\mathrm{PD} 4 \mathrm{H}$, a profundidade de $5-10 \mathrm{~cm}$ foi semelhante estatisticamente às profundidades de 1520 e $20-25 \mathrm{~cm}$, mas as de $15-20$ e $20-25 \mathrm{~cm}$ não diferiram da profundidade de $10-15 \mathrm{~cm}$. A menor densidade foi encontrada na profundidade de $0-5 \mathrm{~cm}$, que, porém, foi semelhante à de 10-15 e 20-25 cm.

No tratamento PC não houve diferença estatística na densidade do solo entre as profundidades, devido à mobilização do solo causada pela ação de arado e grades na camada de 0 a $25 \mathrm{~cm}$ no sistema de preparo convencional.

Segundo proposto por Reinert et al. (2001), o valor crítico de densidade para solos arenosos (com menos de $20 \%$ de argila) é de $1,65 \mathrm{~kg} \mathrm{dm}^{-3}$; no presente estudo, todos os valores de densidade do solo foram inferiores ao valor crítico. Essa menor densidade do solo na camada de $0-5 \mathrm{~cm}$ certamente contribuiu para o maior crescimento do sistema radicular da melancia nessa camada superficial.

Os dados de RP foram coletados em meados de junho de 2009, junto com amostras de densidade do solo, em razão da baixa umidade do solo no período póscolheita, nos meses de março, abril e maio. A RP foi avaliada em sete pontos em linha, perpendiculares à linha de semeadura, distantes $20 \mathrm{~cm}$ entre si, onde o ponto central estava sobre a linha de semeadura, até a profundidade de $40 \mathrm{~cm}$. Os dados estão expressos por tratamento em figuras de superfície de resposta
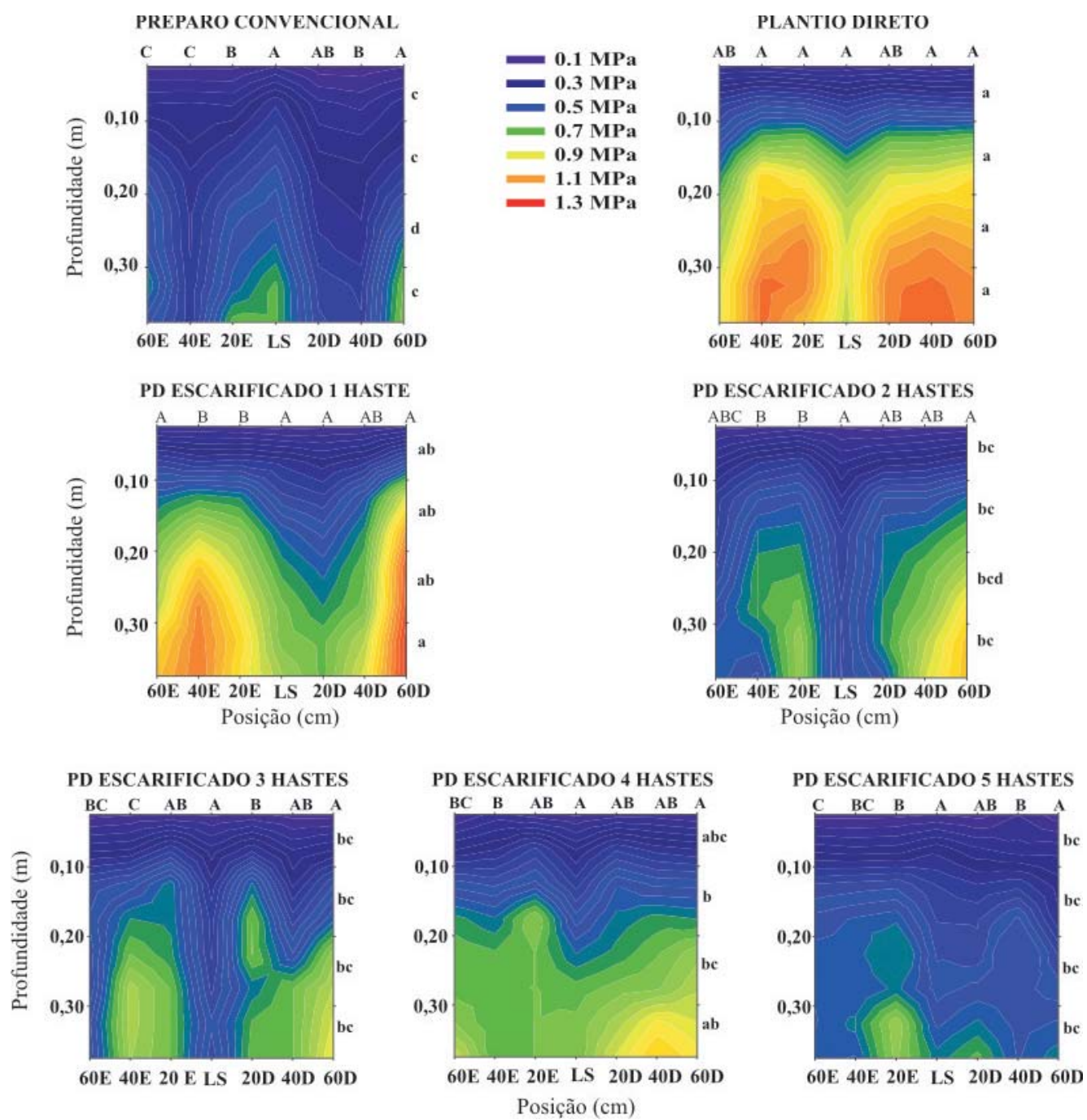

Figura 6. Resistência do solo à penetração em $\mathrm{MPa}$ até $40 \mathrm{~cm}$ de profundidade em pontos alinhados perpendicularmente à linha de semeadura, nos respectivos tratamentos de sistemas de cultivo do solo. (LS: ponto sobre a linha de semeadura; 20E: ponto $20 \mathrm{~cm}$ à esquerda da LS; 40E: ponto $40 \mathrm{~cm}$ à esquerda da LS; 60E: ponto $60 \mathrm{~cm}$ à esquerda da LS; 20D: ponto $20 \mathrm{~cm}$ à direita da LS; 40D: ponto $40 \mathrm{~cm}$ à direita da LS; e 60D: ponto $60 \mathrm{~cm}$ à direita da LS). Letras iguais em maiúscula na horizontal, para a mesma RP, tendo como referência a LS, entre os tratamentos, não diferem significativamente pelo teste de Duncan a $5 \%$; Letras iguais em minúscula na vertical, dentro da mesma faixa de profundidade, não diferem significativamente pelo teste de Duncan a $5 \%$. 
(Figura 6). A análise estatística comparou a RP média de cada ponto perpendicular à linha de semeadura entre os tratamentos, representada horizontalmente sobre as figuras, e também a RP média das faixas de profundidade entre os tratamentos, representada verticalmente, à direita das figuras. Os sete pontos de RP média foram denominados conforme a distância da linha de semeadura: LS é o ponto sobre a linha de semeadura; 20E, o ponto $20 \mathrm{~cm}$ à esquerda da LS; 40E, o ponto a $40 \mathrm{~cm}$ da $\mathrm{LS} ; 60 \mathrm{E}$, o ponto a $60 \mathrm{~cm}$ da $\mathrm{LS}$; $20 \mathrm{D}$, o ponto $20 \mathrm{~cm}$ à direita distante da LS; 40D, o ponto $40 \mathrm{~cm}$ à direita da LS; e $60 \mathrm{D}$, o ponto a $60 \mathrm{~cm}$ da LS.

Para os valores de RP encontrados no ponto $60 \mathrm{E}$, os tratamentos PD, PD1H e PD2H apresentaram semelhança estatística, porém $\mathrm{PD}$ e $\mathrm{PD} 2 \mathrm{H}$ não diferiram de PD3H e PD4H, e também PD2H, PD3H e $\mathrm{PD} 4 \mathrm{H}$ não foram estatisticamente diferentes de $\mathrm{PC}$ e PD5H. No ponto 40E, PD diferiu dos demais tratamentos, apresentando o maior valor de RP média nesse ponto $(0,8130 \mathrm{MPa})$; $\mathrm{PD} 1 \mathrm{H}, \mathrm{PD} 2 \mathrm{H}$ e $\mathrm{PD} 4 \mathrm{H}$ não diferiram de PD5H, o qual por sua vez não diferiu de PC e PD3H. Em 20E, o tratamento PD não diferiu de PD3H e PD4H, porém PD3H e PD4H foram semelhantes a PC, PD1H, PD2H e PD5H.

No ponto LS não houve diferença estatística entre os tratamentos para RP, pois os tratamentos $\mathrm{PC}, \mathrm{PD}$, PD1H, PD2H, PD3H, PD4H e PD5H apresentaram valores de 0,$4777 ; 0,6373 ; 0,5343 ; 0,3313 ; 0,3367$; 0,4821; e 0,4061 MPa, respectivamente, provavelmente devido ao uso da mesma semeadora na implantação da cultura da melancia em todos os tratamentos. No ponto 20D, PD1H apresentou semelhança estatística com os tratamentos PC, PD, PD2H, PD4H e $\mathrm{PD} 5 \mathrm{H}$, os quais, porém, não se diferenciaram de PD3H para os valores de PR. Em 40D, a RP do tratamento $\mathrm{PD}$ não diferiu da de $\mathrm{PD} 1 \mathrm{H}, \mathrm{PD} 2 \mathrm{H}, \mathrm{PD} 3 \mathrm{H}$ e PD4H, que foram semelhantes estatisticamente a PC e PD5H. No ponto $60 \mathrm{D}$, todos os tratamentos foram estatisticamente semelhantes entre si.

Comparando os tratamentos em faixas de profundidade, têm-se as respectivas faixas de $0-10,10-20$, 20-30 e 30-40 cm. Na faixa de profundidade de 0 $10 \mathrm{~cm}$, o tratamento PD não foi diferente de PD1H e $\mathrm{PD} 4 \mathrm{H}$, os quais, porém, não se diferenciaram de PD2H, PD3H e PD5H, e também PD4H foi estatisticamente semelhante a PC. Na profundidade de $10-20 \mathrm{~cm}$, o PD não diferiu estatisticamente apenas de $\mathrm{PD} 1 \mathrm{H}$, mas $\mathrm{PD} 1 \mathrm{H}$ foi semelhante aos tratamentos PD2H, PD3H, PD4H e PD5H, e PD2H, PD3H e PD5H não diferiram de PC. Em 20-30 cm, o PD não se diferenciou de $\mathrm{PD} 1 \mathrm{H}$, que por sua vez não foi diferente de $\mathrm{PD} 2 \mathrm{H}$ e $\mathrm{PD} 4 \mathrm{H}$, os quais foram semelhantes a PD3H e PD5H; contudo, PC, PD2H, PD3H e PD5H não diferenciaram entre si. Na faixa de $30-40 \mathrm{~cm}$, os tratamentos PD e PD1H não diferiram de PD4H, o qual foi semelhante a PD2H, PD3H e PD5H, e estes não diferiram de PC. O tratamento PD4H apresentou sistema radicular restrito devido a provável problema na operação de escarificação, o que pode ser confirmado pela visualização da figura 3 , onde se nota que as hastes do escarificador não tiveram a profundidade alcançada pelos demais tratamentos com escarificador.

Observando o tratamento $\mathrm{PD}$, que obteve valores maiores de RP que os demais, nota-se que isso não foi impedimento para o desenvolvimento do sistema radicular da cultura da melancia, mas certamente causou restrição, pois foi o tratamento com menor área total de raiz.

\section{CONCLUSÕES}

1. Os sistemas de cultivo do solo influenciaram a produtividade da cultura da melancia, sendo o preparo convencional o de maior produtividade, considerando os frutos comercializáveis; o peso médio e a qualidade dos frutos não foram influenciados.

2. A área superficial total de raízes aumentou com a intensidade de mobilização e área mobilizada de solo, exceto para o tratamento PD4H. Aproximadamente $50 \%$ da área superficial total das raízes concentrouse em um raio de $10 \mathrm{~m}$ do colo da planta, em todos os tratamentos. O preparo convencional foi o que mostrou o sistema radicular distribuído de forma mais homogênea, horizontalmente e em profundidade.

3. Após o cultivo da melancia, a densidade do solo apresentou os menores valores na camada de $0-5 \mathrm{~cm}$, exceto no tratamento PC, diferenciando-se das camadas subsequentes. A resistência do solo à penetração diminuiu pelo aumento da mobilização do solo pela escarificação, exceto para PD4H, tanto horizontalmente quanto em profundidade.

\section{LITERATURA CITADA}

ALVARENGA, M.A.R. \& RESENDE, G.M. Cultura da melancia. Lavras, Universidade Federal de Lavras, 2002. 132p. (Textos Acadêmicos, 19)

ARAÚJO NETO, S.E.; HAFLE, O.M.; GURGEL, F.L.; MENEZES, J.B.M. \& SILVA, G.G. Qualidade e vida útil pós-colheita de melancia Crimson Sweet, comercializada em Mossoró. R. Bras. Eng. Agríc. Amb., 4:235-239, 2000.

BROWN Jr, A.C. \& SUMMERS, W.L. Carbohydrate accumulation and color development in watermelon. J. Am. Soc. Hortic. Sci., 110:683-687, 1985.

CARVALHO, R.N. Cultivo de melancia para agricultura familiar. 2.ed. Brasília, Embrapa Informação Tecnológica, 2005. 112p.

CHOUDHURY, E.N. \& OLIVEIRA, C.A. Influência do preparo do solo na produção de melancia e na compactação em Latossolo Vermelho-Amarelo irrigado. Petrolina, Embrapa/CPATSA, 1982. 24p. (Boletim de Pesquisa, 13)

CASTELLANE, P.D. \& CORTEZ, G.E. A cultura da melancia. Jaboticabal, FUNEP/FCAV-UNESP, 1995. 64p. 
COGO, C.M.; ELTZ, F.L.F. \& CASSOL, E.A. Erosividade das chuvas em Santa Maria, RS, determinada pelo índice $\mathrm{EI}_{30}$. R. Bras. Agrometeorol., 14:1-11, 2006.

CRESTANA, S.; GUIMARÃES, M.F.; JORGE, L.A.C.; RALISCH, R.; TOZZI, C.L.;TORRE, A. \& VAZ, C.M.P. Avaliação da distribuição de raízes no solo auxiliada por processamento de imagens digitais. R. Bras. Ci. Solo, 18:365-371, 1994.

ELMOSTROM, G.W. \& DAVIS, P.L. Sugar in developing and mature fruits of several watermelon cultivars. J. Am. Soc. Hortic. Sci., 106:330-333, 1981.

ELTZ, F.L.F.; BOCK, V.D. \& AMADO, T.J.C. Efeito do manejo do solo e de doenças foliares sobre a produção e qualidade da melancia. R. Bras. Agroci., 11:201-206, 2005.

EMPRESA BRASILEIRA DE PESQUISA AGROPECUÁRIA . EMBRAPA. Manual de métodos de análise de solos. 2.ed. Rio de Janeiro, 1997. 212p.

FERNANDEZ, F.M. \& CAPATO, F. Adubação da cultura da melancia: I - Fontes e níveis de adubo orgânico, com e sem aplicações foliar de boro e zinco. Hortic. Bras.,18:845846,2000

INSTITUTO BRASILEIRO DE GEO ESTATISTICA - IBGE. Indicadores conjunturais: Produção agrícola/agricultura. Disponível em: <http://www.ibge.gov.br>. Acesso em: 10 jan. 2010 .

INSTITUTO ADOLFO LUTZ. Métodos físico-químicos para análise de alimentos. 4.ed. São Paulo, p.577-587. Disponível em: <http://www.ial.sp.gov.br/>. Acesso em: 02 fev. de 2010 .

JORGE, L.A.C. \& CRESTANA, S. Recomendações práticas para utilização do SIARCS 3.0 nos estudos de raízes, cobertura vegetal, folhas e outras aplicações. São Carlos, Embrapa-CNPDIA, 1996. 34p. (Recomendação Técnica, 4)

LOPES, C.R.B. Avaliação de cultivares de melancia na Depressão Central do Rio Grande do Sul. Porto Alegre, Universidade Federal do Rio Grande do Sul, 2002. 55p. (Tese de Mestrado)

MOHR, H.C. Watermelon breeding. In: BASSET, M.I Wedtport, Breeding Vegetable Crops, 1986. 584p.

MORENO, J.A. Clima do Rio Grande do Sul. Porto Alegre, Secretaria da Agricultura, Diretoria de Terras e Colonizações, Secção de Geografia, 1961. 46p.
NEVES JUNIOR, A.F. Avaliação da qualidade física de solos em pastagens degradadas da Amazônia. Piracicaba, Escola Superior de Agricultura "Luiz de Queiroz", 2005. 66p. (Tese de Mestrado)

NORTON, J.D.; BOYHAN, G.E.; SMITH, D.A. \& ABRAHAMS, B.R. AU-Sweet scarlet watermelon. HortScience, 30:393394, 1995.

PREVEDELLO, J. Preparo do solo e crescimento inicial de Eucalyptus grandis Hill ex Maiden. em Argissolo. Santa Maria, Universidade Federal de Santa Maria, 2008. 86p. (Tese de Mestrado)

REINERT, D.J.; REICHERT, J.M. \& SILVA, V.R. Propriedades físicas de solos em sistema de plantio direto irrigado. In: CARLESSO, R.; PETRY, M.T.; ROSA, G.M. \& CERETTA, C.A., eds. Irrigação por aspersão no Rio Grande do Sul. Santa Maria, 2001. p.114-133.

RUBIN, R.B.; SILVA, V.R.; REINERT, D.J. \& BACH, A.V. Resistência do solo influenciada pelo tráfego e sistemas de cultivos. In: REUNIÃO SUL-BRASILEIRA DE CIÊNCIA DO SOLO, 2., Santa Maria, 1998. Anais... Santa Maria, 1998.

SÁ, M.A.C. \& SANTOS JUNIOR, J.D.G. Compactação do solo: Conseqüências para o crescimento vegetal. Planaltina, Embrapa Cerrados, 2005. 26p. (Embrapa Cerrado/ Documento, 136)

SASS, P. Fruit storage. Budapeste, Mezogazda Kiado, 1993. $347 \mathrm{p}$.

SCAPINI, C.A.; REINERT, D.J.; REICHERT, J.M.; ZANETTE, A. \& SILVA, V.R. Medição da densidade e porosidade do solo pelo método do cilindro e torrão parafinado em sistemas de preparo do solo e pastejo animal. In: REUNIÃO SUL-BRASILEIRA DE CIÊNCIA DO SOLO, 2., Santa Maria, 1998. Anais... Santa Maria, 1998. p.7-10.

SOCIEDADE BRASILEIRA DE CIÊNCIA DO SOLO. COMISSÃO DE QUÍMICA E FERTILIDADE DO SOLO SBCSRS/SC. Manual de adubação e calagem para os estados do Rio Grande do Sul e Santa Catarina. 10.ed. Porto Alegre, 2004. 400p.

VILLA, W.; GROPPO, G.A.; TESSARIOLI NETO, J. \& GELMINI, G.A. Cultura da melancia. Campinas, CATI, 2001. 52p. (CATI. Boletim Técnico, 243) 